\title{
A EDUCAÇÃO CONTINUADA COMO FERRAMENTA DE QUALIFICAÇÃO DA EQUIPE DE ENFERMAGEM PERANTE A AVALIAÇÃO DA DOR EM IDOSOS
}

\author{
Jéssica Maria Moccelin ${ }^{1}$, Luís Felipe Pissaia ${ }^{2}$, Arlete Eli Kunz da Costa ${ }^{3}$, Sabrina Monteiro, \\ Márcia Jussara Hepp Rehfeldt ${ }^{5}$
}

Resumo: $\mathrm{O}$ presente artigo aborda reflexões referente a assistência ao idoso, com ênfase a prevenção da dor. Tem abordagem qualitativa, com caráter exploratório e descritivo, no qual reflete-se a partir de dados coletados do diário de campo de um pesquisador, na realização de um curso de educação continuada intitulado "Assistência de enfermagem ao idoso: implantação do quinto sinal vital em uma unidade hospitalar". Os sujeitos envolvidos fazem parte de uma equipe de enfermagem em um hospital de médio porte do interior do Rio Grande do Sul, Brasil. Objetiva-se através dele, compartilhar essa experiência como subsidio de qualificação à avaliação da dor em idosos. Partindo desse pressuposto, a ênfase da abordagem teórica faz-se por meio da relevância da educação continuada na área da enfermagem, alicerçada em autores como Bezerra et al. (2012), que tratam das constantes transformações na área da gestão da enfermagem. Além disso, ressalta-se a importância da qualificação da assistência ao idoso com dor, na qual discute-se a necessidade de o profissional da enfermagem estar em constante aperfeiçoamento quanto à demanda exigida por seus clientes. Os resultados obtidos, permitiram, compreender que o curso de educação continuada como estratégia de construção de conhecimento trouxe à tona questões substanciais que ampararam discussões resolutivas concernentes à avaliação da dor em idosos. Em suma, o curso contribuiu para o aperfeiçoamento e atualização na formação dos profissionais, tomando essa construção como alicerce para efetivar e aprimorar a assistência ao individuo com dor.

Palavras-chave: Educação Continuada. Equipe de Enfermagem. Avaliação da Dor. Idosos.

1 Acadêmica de Enfermagem. Univates. Lajeado-RS - Brasil. jessica.moccelin@universo.univates.br

2 Enfermeiro. Mestrando em Ensino. Univates. Lajeado - RS - Brasil. lpissaia@universo.univates.br

3 Enfermeira. Doutora em Ambiente e Desenvolvimento. Univates. Lajeado - RS - Brasil. arlete.costa@ univates.br

4 Licenciada em Ciências Exatas. Mestranda em Ensino. Bolsista contemplada com Taxa PROSUP/ CAPES. Univates. Lajeado - RS - Brasil. sabrinamonteiro1991@gmail.com

5 Doutora em Informática na Educação. Univates. Lajeado - RS - Brasil. mrehfeld@univates.br 


\title{
CONTINUED EDUCATION AS A TOOL FOR THE QUALIFICATION OF THE NURSING TEAM BEFORE THE EVALUATION OF PAIN IN OLDER PEOPLE
}

\begin{abstract}
This article deals with reflections on care for the elderly, with emphasis on pain prevention. It has a qualitative approach, with an exploratory and descriptive character, in which it is reflected from data collected from the field diary of a researcher, in the realization of a continuing education course titled "Nursing care for the elderly: implantation of the fifth vital sign in A hospital unit ". The subjects involved are part of a nursing team in a mid-sized hospital in the interior of Rio Grande do Sul, Brazil. The objective of this study is to share this experience as a qualification grant for the evaluation of pain in the elderly. Based on this assumption, the emphasis of the theoretical approach is made through the relevance of continuing education in nursing, based on authors such as Bezerra et al. (2012), which deal with the constant changes in the area of nursing management. In addition, the importance of the qualification of care for the elderly with pain is highlighted, in which the need for the nursing professional to be constantly improving on the demand demanded by their clients is discussed. The results obtained allowed us to understand that the continuing education course as a strategy of knowledge construction has brought to the fore substantial issues that have supported resolutive discussions concerning the evaluation of pain in the elderly. In short, the course contributed to the improvement and updating of the training of professionals, taking this construction as a foundation for effecting and improving care for the individual with pain.
\end{abstract}

Keywords: Continuing Education. Nursing team. Pain Evaluation. Elderly.

\section{INTRODUÇÃO}

O fenômeno de envelhecimento populacional pode ser constatado em vários países, principalmente na Europa, onde ocorreu uma elevação da expectativa de vida e redução nas taxas de natalidade, configurando aquilo que Santos e colaboradores (2011) denominam como a inversão da pirâmide etária, fazendo suscitar projeções de gastos com esse estrato populacional. Neste sentido o Brasil, segundo dados do Instituto Brasileiro de Geografia e Estatística (IBGE), demonstra um crescimento da população idosa, sendo consistente e sistemático, constituindo-se em 10\% do total, ou seja, 19,6 milhões de pessoas, com estimativas de 66,5 milhões para 2050 , o que significa $29,3 \%$ do contingente etário (IBGE, 2010).

Com o envelhecimento da população e desenvolvimento de tecnologias, houve um aumento da expectativa de vida, que está atrelado ao aumento dos riscos para o aparecimento de vulnerabilidades biológicas, socioeconômicas e psicossociais, acarretadas pelo declínio natural típico da senescência (RODRIGUES; NERI, 2012). Nestas circunstâncias, Santos et al. (2011) discutem estudos a nível mundial onde estimam que $20 \%$ a $50 \%$ dos idosos apresentem problemas relacionados ao aparecimento da dor, sendo que este número pode aumentar para $45 \%$ a $80 \%$ em indivíduos institucionalizados e, em muitos desses casos, a dor não é adequadamente reconhecida e tratada. 
A dor é um sinal subjetivo, e conforme Silva et al. (2015), necessita da atenção integral e diferenciada ao indivíduo para que sejam compreendidas suas dimensões e causas. Neste sentido, a avaliação da dor em idosos transpõe os direitos fundamentados pelo indivíduo, que além de assegurar um cuidado humanizado, também deve ofertar métodos de alívio para o quadro da dor, proporcionando conforto e atendendo às demandas físicas e psicológicas da pessoa (AMAYA-ROPERO; CARRILLOGONZÁLEZ, 2015).

Partindo-se da assertiva anterior, foram criadas diversas escalas que dão subsídios aos profissionais, e segundo Fortunato e colaboradores (2013), estes modelos viabilizam a identificação das alterações presentes no usuário e norteiam suas ações, favorecendo na recuperação e qualidade de vida do indivíduo. Todavia, estudos desenvolvidos por Queiróz et al. (2015), sobre a problemática da avaliação e manejo da dor em idosos na perspectiva de profissionais da saúde, identificam lacunas no conhecimento e na prática assistencial, sendo que a falta de conhecimento e escassez de mecanismos na mensuração da dor dificultam a prestação de um cuidado efetivo e de qualidade.

Concernente a isso, Costa et al. (2012), destacam que a falta de programas de educação continuada (EC) como forma de motivar e preparar a equipe de enfermagem também interferem na qualidade e excelência do cuidado e acrescentam que as instituições ao incentivarem e facilitarem o desenvolvimento de habilidades por meio do conhecimento, estarão buscando novos modelos de gerenciamento, revertendo os resultados em produtividade, qualidade e soluções inovadoras.

Nesta perspectiva, este estudo partiu da busca de transformações da assistência em um cenário de atenção ao idoso, com finalidade de obter informações pertinentes que contribuirão com a implementação de ações futuras com vistas ao adequado controle e a prevenção da dor. Sendo assim, apresenta-se como objetivo compartilhar uma experiência de $\mathrm{EC}$ como subsidio de qualificação da equipe de enfermagem reportada à avaliação da dor em idosos.

\section{FUNDAMENTAÇÃO TEÓRICA}

$\mathrm{Na}$ seção a seguir, tratar-se-á da fundamentação teórica com ênfase na abordagem sobre a relevância da EC na área da enfermagem, além de ressaltar a importância da qualificação da assistência ao idoso com dor.

\section{EDUCAÇÃO CONTINUADA NA ÁREA DA ENFERMAGEM}

A EC na área da saúde vem passando por diversas mudanças paralelamente à evolução que vem ocorrendo em toda a ciência, acarretando impactos nas organizações e nos profissionais, tais como o surgimento de uma sociedade baseada no uso compartilhado de recursos, o que Ferraz, Vendruscolo e Marmett (2014) designam na 
construção coletiva de conhecimento e na valorização do direito à informação, sendo que o produto final é a qualidade do trabalho. Neste sentido, a qualidade vai além dos componentes técnicos e conforme Sardinha Peixoto e colaboradores (2013) torna-se uma equação de diversas variáveis, envolvendo ações de relacionamento interpessoal, de comunicação, trabalho em equipe, ética, segurança do paciente e do profissional e, consequentemente, o desempenho e empenho no âmbito da prática profissional.

Dessa maneira, as instituições de saúde, na gestão de enfermagem estão em constantes modificações na tentativa de se integrarem a este contexto, buscando incorporar como estratégia do processo de trabalho a EC, que segundo Bezerra et al. (2012) fundamenta-se como uma ferramenta facilitadora no desenvolvimento de competência profissional, viabilizando o aprimoramento da assistência. Nesta perspectiva, a EC surge como uma estratégia para preencher as lacunas de conhecimento que perpassaram na formação dos profissionais ou, conforme Krummenauer e outros (2014) são insuficientes para integrarem às necessidades decorrentes das transformações e melhorias dos serviços.

Conforme Bezerra e colaboradores (2012), estudos realizados em hospitais nos EUA, reconheceram que profissionais que trabalham em ambientes que estimulam a construção de conhecimento são mais qualificados em decorrência do investimento e da valorização das pessoas, refletindo na redução da taxa de eventos adversos, no tempo de permanência e mortalidade. Ainda neste contexto, Wegner et al. (2016) salienta a importância da EC com o objetivo de fortalecer a assistência de enfermagem, contribuindo para que os profissionais se sensibilizem em relação às consequências de suas práticas e no processo de redução de riscos em saúde.

Neste panorama, vale destacar que o enfermeiro possui a responsabilidade e dever de acordo com o Código de Ética dos Profissionais de Enfermagem - Resolução COFEN no 311/2007 (p.7): "Art. 69: Estimular, promover, e criar condições para o aperfeiçoamento técnico, científico e cultural dos profissionais de Enfermagem sob sua orientação e supervisão". Sendo assim, é dever do profissional de enfermagem participar do processo educativo, das políticas, projetos e programas das instituições promovendo a sua competência e colaborando no desenvolvimento dos demais integrantes da equipe, além de aprimorar a qualidade da atenção em saúde.

\section{QUALIFICAÇÃO DA ASSISTÊNCIA AO IDOSO COM DOR}

O contínuo aumento da expectativa de vida é uma conquista da sociedade atual, contudo Mendes et al. (2012) prediz que este fenômeno traz inúmeros desafios, gerando adaptações e alterações nos diferentes segmentos sociais. Concomitante a este processo há o aumento na incidência de agravos à saúde desta população e como consequência, os idosos têm o maior índice de internações hospitalares, principalmente nos casos agudos das doenças (MENDES et al., 2012). No que tange ao paciente idoso, Besse, Cecilio e Lemos (2014) delimitam que esta população necessita de cuidados diferenciados 
e reconhecimento de suas especificidades, demandando do profissional que presta o atendimento maior sensibilidade e perspicácia.

Entretanto, um estudo realizado por Lima et al. (2010) sobre a humanização no cuidado ao idoso, menciona um déficit no serviço humanizado, enfatizando aspectos que referem-se a falta de comunicação e privacidade na hora da execução dos procedimentos, a forma indelicada em que os profissionais agem, falta de instalações adequadas dos serviços, carência de programas específicos e de recursos humanos, entre outros. Assim, configura-se a importância da qualificação de recursos humanos voltada para o desenvolvimento das competências necessárias ao cuidado à saúde do idoso, considerando suas complexidades e peculiaridades (GIRO; PAÚL, 2013).

Diante do exposto, Carvalhais e Sousa (2011) comentam que o cuidado e a preocupação ao idoso com dor não pode se limitar apenas aos aspectos biológicos, sendo essencial que os profissionais da saúde atuem de forma multidisciplinar e interdisciplinar, sendo necessário observar os aspectos físicos, psicológicos e sociais. Neste sentido, Fortunato e colaboradores (2013) comenta sobre a importância da EC como forma de qualificar a equipe de saúde que presta assistência aos indivíduos com dor, pois o processo de identificação torna-se amplo e subjetivo e passível de erros caso não for avaliado rigorosamente.

Partindo desse pressuposto, o profissional de enfermagem possui a necessidade de estar em constante aperfeiçoamento quanto à demanda exigida por seus clientes. Neste cenário, Both e colaboradores (2014) identificam que os direcionamentos educativos se caracterizam por serem contínuos e visam remodelar o desempenho dos profissionais, tornando-os proativos e com capacidade reflexiva acerca da prática, favorecendo a transformação das situações vivenciadas. Sobretudo, Hetti e outros (2013) destacam o desafio para o planejamento de programas de EC, principalmente pela escassez nos currículos de formação dos cursos da saúde, de conteúdos e cenários de prática concernente à geriatria e gerontologia.

\section{METODOLOGIA}

Este estudo tem um caráter exploratório e descritivo, com abordagem qualitativa. Os dados foram coletados do diário de campo do pesquisador em ocasião da realização de um curso de EC para a equipe de enfermagem em um hospital de médio porte do interior do Rio Grande do Sul, Brasil.

O curso de EC foi proposto por meio do projeto de pesquisa intitulado "Assistência de enfermagem ao idoso: implantação do quinto sinal vital em uma unidade hospitalar", possuindo anuência da instituição hospitalar estudada, aprovação pelo Comitê de Ética em Pesquisa (COEP) da Universidade do Vale do Taquari UNIVATES por meio da CAAE no 69285317.6.0000.5310. Ainda observaram-se os aspectos éticos que envolvem estudos com seres humanos previstos pela Resolução 466 de 2012. 
O curso possuiu uma carga horária de quatro horas, sendo realizado no mês de agosto de 2017 em auditório da própria instituição hospitalar. Na ocasião participaram 18 profissionais da equipe de enfermagem atuantes em todos os setores, enfatizando que o grupo foi composto por participantes de nível médio e graduação. Para a realização do curso, houve a aprovação da coordenação geral de enfermagem da instituição, sendo agendado em data específica e disponibilizado o tempo necessário para a participação dos profissionais.

Para a realização do curso, os pesquisadores utilizaram-se de recursos audiovisuais, tais como, computador e projetor, sendo que os conteúdos foram expostos por meio do programa PowerPoint. O conteúdo central do curso de EC foi a avaliação da dor em idosos atendidos na instituição hospitalar, sendo contextualizado por meio de resultados de estudos nacionais e internacionais em consonância com a realização de reflexões com a prática assistencial realizada atualmente no local.

Para a efetuação deste estudo, utilizou-se das anotações realizadas no diário de campo do pesquisador, por meio do qual se resguardou sentimentos explicitados durante o curso. Em relação a este método, Oliveira e Fabris (2017) o definem como uma ferramenta que permite sistematizar as experiências e busca abarcar a intensidade e não apenas a extensão do fenômeno estudado. Respeitando-se os critérios éticos previstos no projeto de pesquisa, utilizou-se de codinomes para identificar os participantes, sendo utilizada a letra "E" maiúscula, seguida de números arábicos aleatórios.

A análise das informações foi realizada por modalidades de pontos focais compatíveis, conforme a Análise de Conteúdo de Bardin (2011). Sendo que esta técnica de investigação organiza-se em três fases: Pré-análise; Exploração do material; Tratamento dos resultados obtidos e interpretação. A partir deste processo as informações serão anexadas ao diário de campo do pesquisador que descreverá os dados, explorando-os através de materiais científicos relevantes.

\section{RESULTADOS E DISCUSSÃO}

Neste item, serão apresentadas as reflexões sobre a proposta do curso de EC, apresentando-se os resultados obtidos, por meio de falas dos próprios profissionais. Disserta-se sobre o reconhecimento da dor como quinto sinal vital, em seguida os aspectos subjetivos do indivíduo na avaliação da dor e ao final, os instrumentos utilizados para avaliar a experiência dolorosa.

\section{Reconhecimento da dor como quinto sinal vital}

Ao iniciar a capacitação, o pesquisador expôs a necessidade de tornar a verificação da dor como uma rotina, dentre os sinais vitais já incorporados na instituição. Destacando ainda, o embasamento teórico sobre a classificação da dor como quinto 
sinal vital, dentre os demais. Ao questionar os participantes sobre a necessidade de avaliação deste sinal juntamente com os demais, E6 destaca: "Acredito que a dor faça parte dos demais sinais vitais, assim como já existem estudos que comprovam isso". Reforçando a ideia exposta anteriormente E10, refletindo sobre sua prática expõe: "Eu avalio ela como muito importante, tendo em vista que a qualidade de vida da pessoa vai mudar tanto no intra como no extra-hospitalar".

Grande parte dos participantes identificou a dor como quinto sinal vital, assim devendo ser avaliado, registrado e tratado regularmente como os outros parâmetros fisiológicos, embora não o faça habitualmente. Estudos mostram a relevância da avaliação da dor com os outros sinais vitais, tornando-se um critério obrigatório na rotina dos profissionais. Araujo e Romero (2015) infere que a identificação da dor seria o primeiro passo para um registro adequado sobre a sua tipologia, sua intensidade e repercussão na qualidade de vida do paciente.

Repensando sobre sua prática assistencial e necessidade de avaliação da dor, E2 indica o seguinte argumento: "Eu reconheço a dor como quinto sinal vital e considero ela tão importante quanto os demais sinais vitais, porque conforme a sua intensidade ela pode repercutir de diversas formas na vida do individuo, podendo mudar as suas expressões, o modo de agir e pensar, influenciando diretamente nos valores de outros sinais vitais como pressão arterial, frequência cardiaca e frequência respiratória".

No contexto da assistência aos idosos, os sinais vitais são indicadores que merecem cautela, devido à grande oscilação em sua saúde fisiológica, cognitiva e psicossocial (TEIXEIRA et al., 2015). Sob este aspecto, Queiróz e colaboradores (2015) comenta que é notável que a dor produz repercussões fisiológicas e psicológicas, sendo necessário considerar a pessoa não somente como um corpo biológico, numa visão reducionista e fragmentada. É premente a necessidade de o profissional ter uma visão holística, multi e interdisciplinar do ser humano na sua integralidade (QUEIRÓZ et al., 2015).

Ainda sobre a rotina de trabalho, E4 destaca em sua fala que possui consciência da necessidade de avaliar a dor, no entanto alguns empecilhos, como o excesso de trabalho influenciam na sua avaliação, conforme o relato: "Teoricamente eu sei que é o quinto sinal vital, mas com o passar dos dias, na prática, o tempo acaba se tornando limitado por conta do excesso de trabalho então você acaba não usando mais o sinal vital de dor [...] normalmente eu só pergunto se o paciente está sentindo dor sim ou não e se aliviou".

No setor da saúde torna-se frequente que os profissionais possuam vários vínculos empregatícios, seja pela disponibilidade de horário e/ou pela necessidade de complementar a renda, acarretando em excesso de trabalho e jornada de trabalho longa e exaustiva (FERREIRA; LUCCA, 2015). Além desses fatores que resultam no excesso de trabalho e consequentemente comprometem a qualidade do cuidado prestado, Pires e colaboradores (2016), trazem em seu estudo que a escassez de recursos humanos, o déficit na estrutura física, a carência de materiais e equipamentos e a falta de autonomia e motivação também refletem nesse processo. Atrelado a isso, 
estes profissionais tornam-se mais vulneráveis à ocorrência de acidentes de trabalho, tornando-se necessário repensar as práticas em saúde e a estrutura dos serviços.

\section{Aspectos subjetivos do indivíduo na avaliação da dor}

O pesquisador destacou no curso a importância de observar os sinais e sintomas que levam a avaliação da dor, dentre estes, a credibilidade pelos argumentos verbais explicitados pelo próprio idoso. Em suma, E7 destaca dificuldade em levar este último aspecto em consideração, conforme a fala: "Uma questão que eu percebo no meu dia a dia é a de acreditar na queixa do paciente, confiar no que ele está relatando". Ainda assim a participante E7 reforça a ideia anterior, expondo exemplos de sua rotina e que esclarecem a preocupação, conforme o relato: "Ás vezes ele está com um sorriso no rosto e menciona ter uma dor 10, por exemplo [...] você percebe pelas expressões dele que não é verdade, porém, por mais que você perceba que aquela dor não é real, é necessário dar continuidade ao atendimento como se fosse, porque muitas vezes aquela dor pode estar associada com o emocional daquele individuo".

Os relatos acima nos convidam a refletir que o estudo da dor se configura em uma área ampla, complexa e desafiadora, para os profissionais da saúde. Desta forma, o olhar clínico e a educação continuada são estratégias que podem auxiliar os profissionais a avaliar a dor do paciente, observando os sinais que apresentam e os comportamentos e atitudes que expressam. Neste contexto, Padilha, Kreinpaul e Petry (2013) trazem que a avaliação inadequada da intensidade da sintomatologia dolorosa pode levar a condutas e a uma terapêutica inadequada, sendo que pode haver excesso de valorização com implementação excessiva de medicação ou, pelo contrário, falta de atenção e, mais precisamente, de apoio emocional.

Ainda neste mesmo limiar, E11 destaca em seu relato a dificuldade em assimilar o relato verbal de dor, após a administração medicamentosa, sendo que na maioria dos casos, a terapia farmacológica atua beneficamente perante este sinal, conforme a fala: "Ás vezes fica complicado acreditar naquilo que o paciente está te referindo, quando você administra uma série de medicamentos, desde os não opióides até os opióides mais fortes, como a morfina, e o paciente continua referindo dor [...] será que essa dor realmente é verdadeira?".

A administração analgésica não consiste, necessariamente, como única forma de terapêutica na intervenção da dor, podendo desenvolver-se outras ações associadas que apresentem maior êxito. $\mathrm{O}$ manejo da dor torna-se mais efetivo quando envolve estratégias múltiplas, que atuam nas diversas dimensões desta. Sob este limiar, pode-se citar as intervenções não farmacológicas que compreendem um conjunto de medidas de ordem física, educacional e emocional (OLIVEIRA et al., 2016).

Contrapondo a ideia anterior, E6 destaca uma experiência própria em que a administração de fármacos não se mostrou resolutiva perante a dor, conforme o trecho: 
"Mas quando eu sofri um acidente de carro, mesmo com morfina eu continuava sentindo dor e eu não estava fingindo ela".

A cultura está intimamente ligada na tolerância ou não da dor, ou seja, a perspectiva, a expressão e a forma como o paciente lida com o fenômeno doloroso estão estreitamente relacionadas com o conceito que ele tem sobre ela. Este aspecto, conforme Fortunato e colaboradores (2013) pode ser verificado em situações nas quais estímulos, que produzem sensações insuportáveis para uma pessoa, podem ser toleráveis para outra. Sendo assim, é necessário que a equipe de enfermagem seja conhecedora dos aspectos culturais, emocionais e educacionais que fazem parte no contexto do individuo, facilitando a qualidade e resolutividade da assistência ofertada.

A subjetividade da avaliação da dor esteve presente nestas discussões, ao passo que, induz-se a necessidade de capacitação profissional a fim de realizar uma leitura adequada deste sinal. Sobre este quesito, E12 incorpora a experiência profissional, e expõe para o grupo a necessidade de reflexão sobre a avaliação da dor, por tratar-se de um sinal subjetivo, conforme a fala: "Eu sempre avalio a dor durante os atendimentos por meio do relato do paciente, porque não existe nenhum instrumento, como no caso do termômetro ou esfigmo, que me expresse um valor, ou seja, eu tenho que acreditar naquilo que ele está me falando, mesmo percebendo que em alguns casos as suas expressões não condizem com aquilo que está sendo relatado".

Como demonstra o relato acima, existem profissionais que consideram a dor por meio do relato e expressões corporais. Neste contexto, identificar os indícios sugestivos de sensação dolorosa contribui com o tratamento, entretanto, por tratar-se de uma experiência intrínseca, o processo de acreditar na queixa do outro torna-se complexo, sendo necessário observar os sinais verbais e não-verbais.

Pelo fato da dor ser uma experiência subjetiva, somente quem a sente pode expressá-la e, portanto, sua avaliação não deve ser negligenciada. Em alguns casos, há indivíduos que não desejam que a equipe de enfermagem identifique sua dor e, consequentemente, acabam suprimindo os sinais de sofrimento, todavia, isso não significa ausência dela e nem impede que ela seja avaliada (QUEIRÓZ et al., 2015). No que tange a esse processo, Padilha, Kleinpaul e Petry (2013), ressaltam que por meio de uma abordagem criteriosa é possível identificar o motivo pelo qual ocorre essa negação e assim, conhecendo suas crenças e cultura será possível minimizar os medos e inquietações que afligem a pessoa.

Outra questão abordada pelos participantes diz respeito aos conhecimentos acerca da dor aguda e a crônica, de acordo com as suas vivências. Isto pode ser identificado pela fala de E14: "Eu acho que a pessoa idosa vai sentir mais dor, geralmente eles tem uma dor cronificada [...] mesmo se eles estiverem só com tosse, por exemplo, eles vão relatar outros tipos de dores".

Os idosos constituem a população mais acometida pelas doenças crônicas, representando um desafio para os profissionais da saúde. Nesse sentido, Barbosa e outros 
(2011) trazem que para o alívio da dor crônica, somente os agentes farmacológicos não são eficazes, devendo ser repensadas as estratégias de saúde que são empregadas para minorar a sensação dolorosa. Ressalta-se que o alívio da sensação álgica e a promoção de conforto são intervenções fundamentais que envolvem, além do conhecimento científico e habilidade técnica, questões humanitárias e éticas da prática em saúde (NASCIMENTO; SILVA, 2014).

\section{Instrumentos utilizados para avaliar a experiência dolorosa}

Para a realização do curso de EC, o pesquisador reservou boa parte da aula para demonstrar as principais maneiras de avaliar a dor em idosos. Primeiramente mostrouse a Escala Verbal Numérica, a qual permite quantificar a intensidade da dor usando números. $\mathrm{O}$ ponto 0 (zero) representa nenhuma dor e 10 (dez) representa a dor mais intensa, a pior possível. Os outros números representam quantidades intermediárias de dor, como leve e moderada que segundo Fortunato et al. (2013), pode ser aplicada gráfica ou verbalmente (Imagem 1).

Em seguida, mostrou-se a Escala de Faces de Dor, em concordância com Leão e Chaves (2004), esta possibilita o indivíduo a analisar as imagens e indicar qual delas se relaciona à dor que o mesmo está sentindo. Em relação a esta escala ela mostra-se como alternativa fidedigna para avaliar a dor em indivíduos com baixo nível educacional e com ou sem alterações cognitivas leves (Imagem 2).

Além destas escalas que são consideradas unidimensionais, ou seja, que quantificam a experiência dolorosa em uma só dimensão, foram explanados na apresentação alguns instrumentos multidimensionais, como é o caso do Questionário de dor McGill. Conforme Martinez, Grassi e Marques (2011), este instrumento procura descrever experiências dolorosas por meio do auto relato, utilizado para responder ao questionário específico, que engloba os quesitos sensoriais, afetivos e de avaliação (Imagem 3).

Imagem 1 - Escala Verbal Numérica

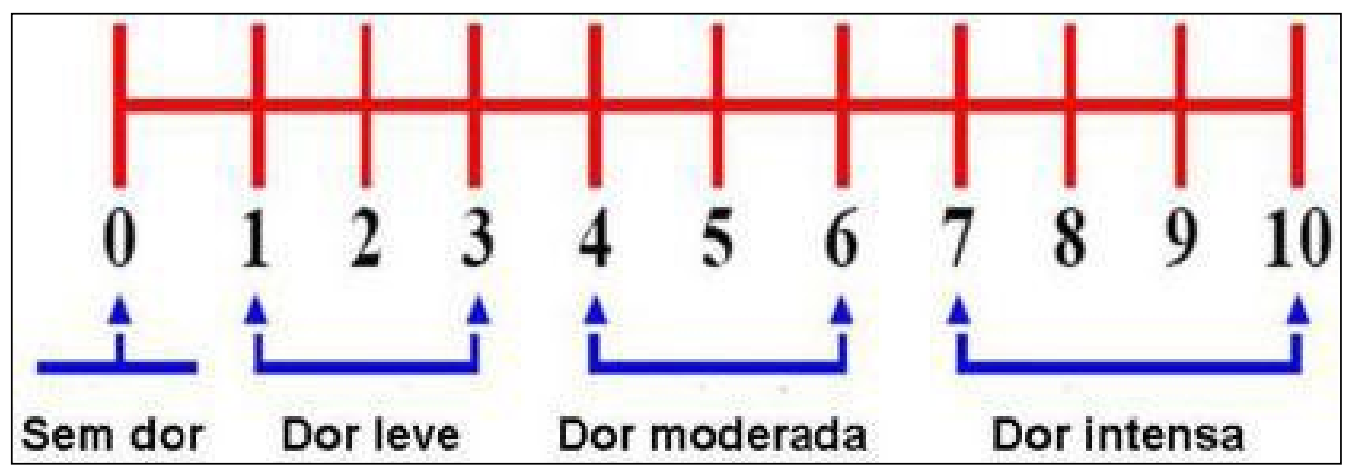

Fonte: FORTUNATO et al. (2013). 
Imagem 2 - Escala de Faces de Dor

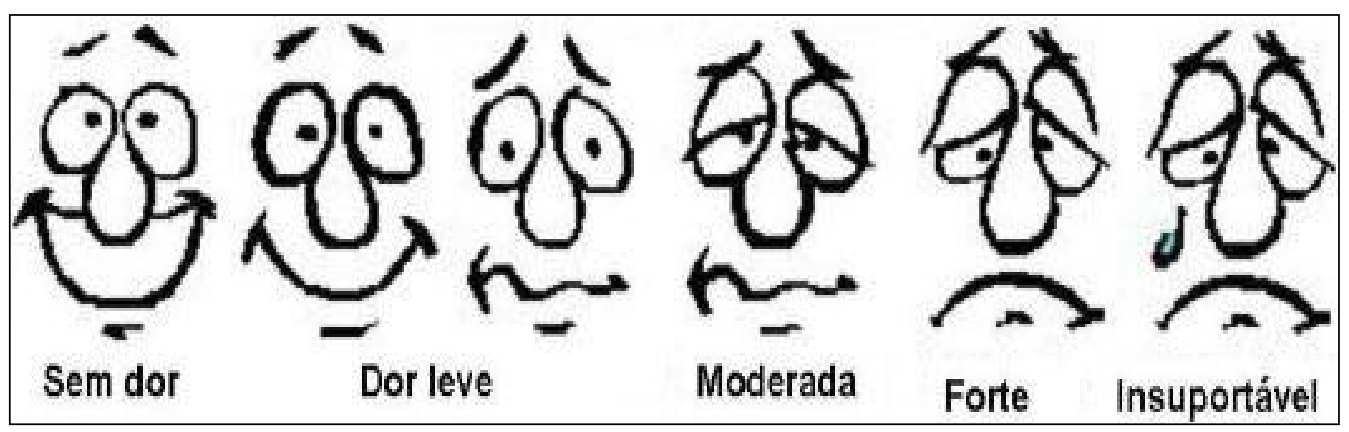

Fonte: FORTUNATO et al. (2013).

Imagem 3 - Questionário de dor McGill

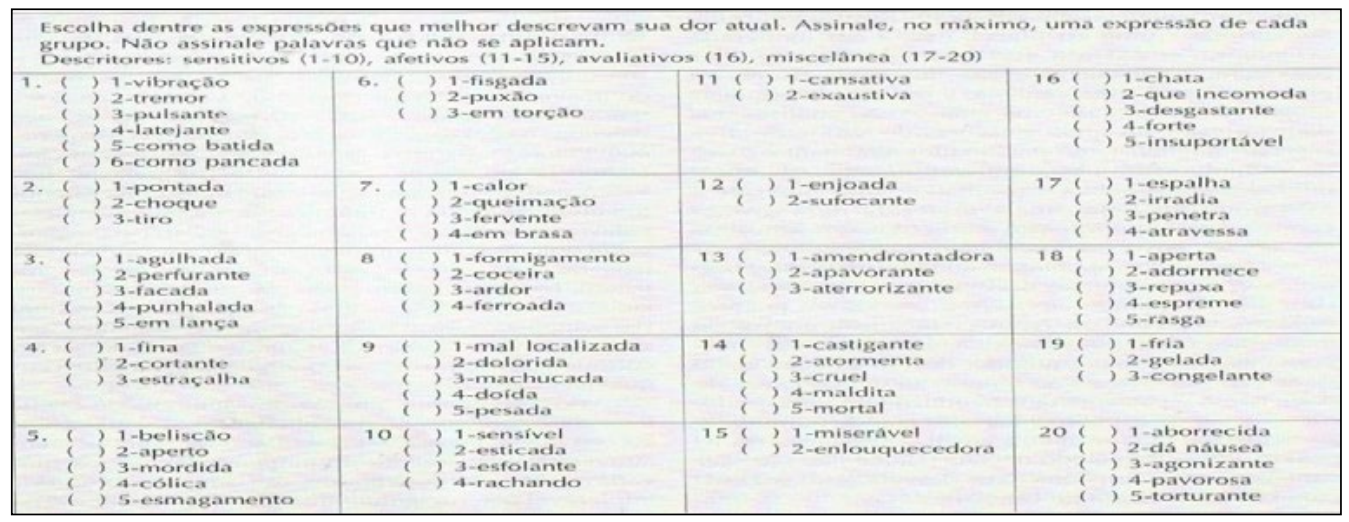

Fonte: LEÃO; CHAVES (2004).

No que concerne sobre estes instrumentos destinados para avaliação da dor, Fortunato e colaboradores (2013), destacam que eles devem dar subsídios ao profissional, pois desta forma será possível identificar as alterações presentes no paciente e usar a intervenção adequada. Baseado nisto, infere-se que o profissional deva estar capacitado a fim de saber aplicar a escala e interpretá-la de maneira correta.

É válido ressaltar que, não estava estabelecida na rotina hospitalar a utilização de instrumentos para avaliação e quantificação da dor pelos profissionais, ou seja, apenas a mensuração dos sinais vitais clássicos fazia parte da prática de enfermagem, enquanto que o registro da dor e seu manejo sistemático permaneciam exclusos nas avaliações. Sendo assim, foram disponibilizadas para estes profissionais algumas cópias de uma escala que surgiu a partir da agregação das escalas verbal numérica e de faces, sendo orientado quanto a sua correta aplicação e a importância de realizar os registros sistemáticos para que as informações permeiem entre a equipe. 


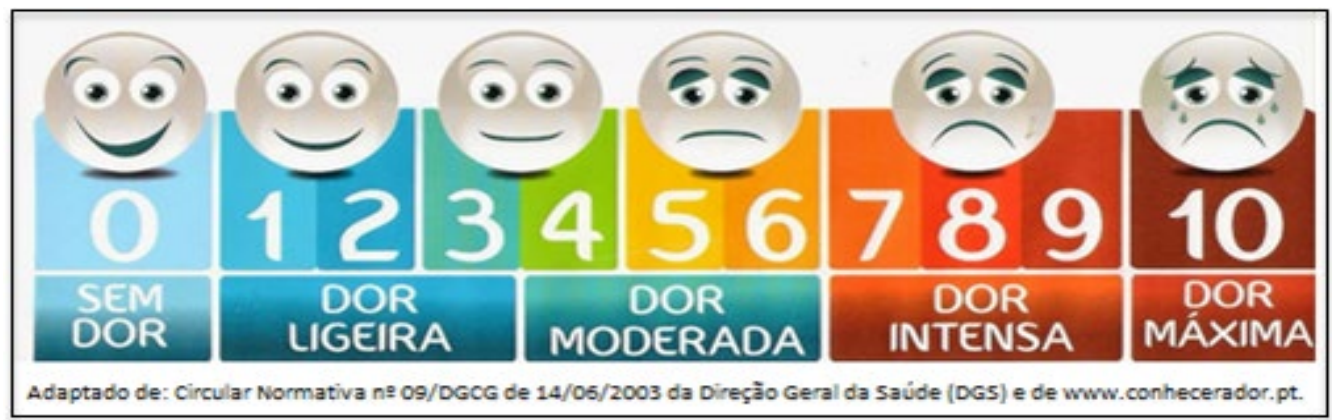

Fonte: Imagem disponível na Internet ${ }^{6}$

Por meio da explanação, alguns comentários surgiram sobre a utilização nos diferentes espaços de trabalho, por exemplo, E9 comenta sobre a sua avaliação perante a pessoa idosa, destacando os pontos principais do processo, conforme a fala destacada: "Durante todos os atendimentos às pessoas eu avalio a dor, seja observando as expressóes faciais, ouvindo o auto relato delas, sendo que na maioria das vezes elas já mencionam se têm dor ou até mesmo questionando de forma indireta o grau da sensação dolorosa em um limiar de $\mathrm{O}$ a $10 "$.

Este relato nos permite elencar que, existe uma grande variedade de estratégias que subsidiam os profissionais na avaliação da dor, como o auto relato do idoso, a observação das expressões faciais e corporais pelo profissional, além das escalas unidimensionais e multidimensionais, sendo que apenas estas últimas são capazes de quantificar o grau da algia experienciado pelo paciente. Com relação às escalas, Queiróz et al. (2015) mencionam que o profissional deve estar atento para a indicação de cada uma delas, pois existem diversos fatores a serem observados e avaliados antes de proceder a mensuração da dor, devendo ser consideradas as particularidades de cada indivíduo.

Embora não tenha sido amplamente referenciado, um número significativo dos profissionais que participaram do estudo salientou a importância da formação, do preparo científico para a aplicação de escalas de avaliação da dor, no entanto, os mesmos participantes comentaram que nas instituições de ensino onde frequentaram, o aprendizado sobre esta avaliação foi de forma inconstante e reduzido. A esse respeito, fica explícito que a falta de informação tem sido uma barreira na avaliação e tratamento adequado da dor.

Neste sentido, o processo que envolve o ensino-aprendizagem para o desenvolvimento de habilidades e competências, são construções iniciais na formação e ampliadas no decorrer da prática profissional, o que exige do profissional o compromisso

6 Imagem disponível na Internet. Disponível em: http://www.carlosedgar.com/2014/05/avaliacao-dador-no-sape.html. Acesso em: 30 mai 2017. 
com a atualização, de modo a oferecer ao indivíduo alternativas eficazes para o manejo da dor (BOTTEGA; FONTANA, 2010). Percebe-se então, a importância do profissional atualizar seus conhecimentos pela educação continuada em saúde, como uma estratégia para sanar a falta de conhecimento, tornando-se um dispositivo capaz de promover a construção e reconstrução de saberes.

Nas demais observações realizadas pelos participantes não se observou uma técnica delimitada de avaliação da dor, estando esta mensuração presente, no entanto com riscos de não ser efetiva, conforme relato de E1: "Eu costumo utilizar a avaliação da dor de forma indireta [...] está com dor, está sem dor? Melhorou? Piorou? Mas nada que seja quantificado". A principal finalidade da avaliação da dor deve ser proporcionar alívio e conforto do idoso por meio de ações eficazes, sendo assim, é necessário que a sua identificação e tratamento sejam interdependentes. Além disso, estratégias de tratamento da dor, utilizadas sem uma avaliação sistemática da mesma não são eficazes ou adequadas (PEREIRA E SILVA et al., 2007). Outro exemplo verificado sobre a inconsistência na verificação da dor em idosos foi a da fala do profissional E8, predizendo o seguinte: "Quando o paciente chega, costumo já pedir qual é a queixa e, geralmente, eles já chegam relatando algum tipo de dor, mas na teoria nunca tinha ouvido falar sobre como avaliar a dor nos pacientes, então eu questiono porque faz parte do meu senso".

Estudo demonstra resultados análogos, de modo que a maioria dos profissionais desconhece os instrumentos para a mensuração da dor (QUEIRÓZ et al., 2015). Sendo que estes por sua vez acabam se respaldando no senso comum, nas próprias crenças, proposições e vivências acumuladas. Desta forma, há necessidade que a equipe de enfermagem seja conhecedora de sua responsabilidade frente ao usuário com dor, fazendo uso de plano de cuidados sistematizados para a avaliação, contribuindo para uma melhor evolução do indivíduo, proporcionando um tratamento humanizado e eficaz (SAÇA et al., 2010)

\section{CONSIDERAÇÕES FINAIS}

A equipe de enfermagem possui papel primordial no controle da dor no idoso, atuando na avaliação, intervenção e monitorização dos resultados da terapêutica, de modo que esta nunca deve ser negligenciada. Além disso, eles são fundamentais para que as informações sobre a dor do paciente permeiem por toda equipe de saúde. Todavia, a educação e o conhecimento teórico devem estar atrelados à prática.

Os resultados desse estudo permitiram, compreender que a equipe de enfermagem do hospital pesquisado retratam os conhecimentos incipientes referente às formas de avaliar a dor, apesar de a reconheceram como quinto sinal vital, eles não a avaliam sistematicamente. Neste contexto, a falta de conhecimento constitui-se como um desafio para o cuidar em enfermagem, sendo que a educação em saúde é uma estratégia capaz de promover esta qualificação e reciclagem no processo do saber. 
Para que o cuidado de enfermagem seja prestado de forma humanizada, qualificada e resolutiva em relação ao idoso que sofre com dor, é crucial que haja uma formação adequada e educação continuada sobre a temática em foco, pois dessa forma será factível a produção de conhecimentos que levem a uma concepção expressiva da experiência dolorosa e os métodos mais eficazes para promover o seu alívio e conforto.

Considera-se que o curso de educação continuada como estratégia de construção de conhecimento trouxe à tona questões substanciais que ampararam discussões resolutivas concernentes à avaliação da dor em idosos. Em suma, o curso contribuiu para o aperfeiçoamento e atualização na formação dos profissionais, tomando essa construção como alicerce para efetivar e aprimorar a assistência ao individuo com dor.

\section{REFERÊNCIAS}

AMAYA-ROPERO, M. C.; CARILLO-GONZÁLEZ, G. M. Apoyo social percibido y afrontamiento en personas con dolor crónico no maligno. Chía, Colombia, v. 15, n.4, p.461474, 2015.

ARAUJO, L. C.; ROMERO, B. Dor: avaliação do quinto sinal vital. Uma reflexão teórica. Revista Dor, São Paulo, v. 16, n. 4, 2015.

BARBOSA, M. H. et al. Avaliação da dor crônica em idosos institucionalizados. Revista Mineira de Enfermagem, v. 16, n. 1, p. 63-68, 2012.

BARDIN, L. Análise de Conteúdo. 70. Ed. São Paulo: Edições, 2011.

BESSE, M., CECÍLIO, L.C.de O.; LEMOS, N.D. A Equipe Multiprofissional em Gerontologia e a Produção do Cuidado: um estudo de caso. Revista Kairós Gerontologia, v. 17, n. 2, p. 205-222, 2014.

BEZERRA, A. L. Q. et al. O processo de educação continuada na visão de enfermeiros de um hospital universitário. Rev. Eletr. Enf., v. 14, n. 3, p. 618-25, 2012.

BOTH, J. E. et al. Qualificação da equipe de enfermagem mediante pesquisa convergente assistencial: contribuições ao cuidado do idoso hospitalizado. Escola Ana Nery Revista de Enfermagem, v. 18, n. 3, 2014.

BOTTEGA, F. H.; FONTANA, R. T. A dor como quinto sinal vital: utilização da escala de avaliação por enfermeiros de um hospital geral. Texto Contexto Enferm, Florianópolis, v. 19, n. 2, p. 283-290, 2010.

CARVALHAIS, M. D.; SOUSA, L. Promover a qualidade de cuidados de enfermagem a pessoas idosas hospitalizadas. Rev. Enf. Ref., Coimbra, v. 3, n. 3, p. 75-84, 2011.

COFEN - Resolução COFEN no. 311/2007: Código de Ética dos Profissionais de

Enfermagem. Disponível em: http:// www.portalcofen.gov. Acesso em: 12 ago. 2017.

COSTA, D. B. et al. Custo de educação continuada para equipe de enfermagem de um hospital universitário público. Rev. Eletr. Enf., v. 14 n. 2, p. 257-66, 2012. 
FERRAZ, L.; VENDRUSCOLO, C.; MARMETT, S. Educação permanente na enfermagem: uma revisão integrativa. Revista Baiana de Enfermagem, Salvador, v. 28, n. 2, p. 196-207, 2014.

FERREIRA, N. N.; LUCCA, S. R. Síndrome de burnout em técnicos de enfermagem de um hospital público do Estado de São Paulo. Rev. Bras. Epidemiol., v. 18, n.1, p. 68-79, 2015.

FORTUNATO, J. G. S. et al. Escalas de dor no paciente crítico: uma revisão integrativa, Revista Hupe, Rio de Janeiro, v. 12, n. 3, p. 110-117, 2013.

GIRO, A.; PAÚL, C. Envelhecimento sensorial, declínio cognitivo e qualidade de vida no idoso com demência. Actas de Gerontologia. v.1, n.1, p.1-10, 2013.

HETTI, L. B. et al. Educação permanente/continuada como estratégias de gestão no Serviço de Atendimento Móvel de Urgência. Revista Eletrônica de Enfermagem, v. 15, n. 4, p. 973982, 2013.

IBGE: Síntese de Indicadores Sociais: Uma Análise das Condições de Vida da População Brasileira, 2010. Disponível em: http://www.ibge.gov.br/home/presidencia/noticias/imprensa/ ppts/0000000144.pdf. Acesso em: 12 ago. 2017.

KRUMMENAUER, E. C. et al. Educação continuada: Uma ferramenta para a segurança do cuidado. Rev Epidemiol Control Infect., v. 4, n. 3, p. 221-222, 2014.

LEÃO, E.; CHAVES, L. D. Dor: 5º sinal vital: reflexões e intervenções de enfermagem. Curitiba, Editora: Maio, 2004.

LIMA, T. J. V. et al. Humanização na Atenção à Saúde do Idoso. Saude soc., São Paulo, v. 19, n. 4, p. 866-877, 2010.

MARTINEZ, J. E.; GRASSI, D. C.; MARQUES, L. G. Análise da aplicabilidade de três instrumentos de avaliação de dor em distintas unidades de atendimento: ambulatório, enfermaria e urgência. Rev. Bras. Reumatol., v. 51, n. 4, p. 304-308, 2011.

MENDES, A. C. G. et al. Assistência pública de saúde no contexto da transição demográfica brasileira: exigências atuais e futuras. Cad. Saúde Pública, Rio de Janeiro, v. 28, n. 5, 2012.

NASCIMENTO, J. C. C.; SILVA, L. C. S. Avaliação da dor em pacientes sob cuidados em Unidades de Terapia Intensiva: uma revisão de literatura. Revista Movimenta, v. 7, n. 2, 2014.

OLIVEIRA, C. W. L. et al. Intervenções não farmacológicas no alivio da dor em unidade de terapia intensiva neonatal. Ciências Biológicas e da Saúde, v. 3, n. 2, p. 123-134, 2016.

OLIVEIRA, S.; FABRIS, E. H. Práticas de iniciação à docência: o diário de campo como instrumento para pensar a formação de professores. Rev. Diálogo Educ.,Curitiba, v. 17, n. 52, p. 639-660, 2017.

PADILHA, D. B.; KLEINPAUL, W. V.; PETRY, A. R. Possibilidades e desafios enfrentados pelo profissional de enfermagem no atendimento ao paciente com sintomatologia dolorosa. Revista Eletrônica de Enfermagem do Vale do Paraíba, v. 1, n. 5, 2013. 
PEREIRA E SILVA, Y. et al. Avaliação da Dor em Neonatologia. Rev Bras Anestesiol.,v. 57, n. 5, p. 565-574, 2007.

PIRES, D. E. P. et al. Cargas de trabalho da enfermagem na saúde da família: implicações no acesso universal. Rev. Latino-Am. Enfermagem, v. 24, 2016.

QUEIRÓZ, D. T. G. et al. Dor - 5o sinal vital: conhecimento de enfermeiros. Revista de Enfermagem, Recife, v. 9, n. 4, p. 7186- 7192, 2015.

RODRIGUES, N.; NERI, A. L. Vulnerabilidade social, individual e programática em idosos da comunidade: dados do estudo FIBRA, Campinas, SP, Brasil. Ciênc. saúde coletiva, v.17, n.8, p. 2129-2139, 2012.

SAÇA, C. S. et al. A dor como 5o sinal vital: atuação da equipe de enfermagem no hospital privado com gestão do Sistema Único de Saúde (SUS). J health sci inst, v. 28, n. 1, p. 35-41, 2010.

SANTOS, F. et al. Programa de autogerenciamento da dor crônica no idoso: estudo piloto.

Rev. Dor. São Paulo, v. 12, n. 3, p. 209-214, 2011.

SARDINHA PEIXOTO, L. et al. Educação permanente, continuada e em serviço: desvendando seus conceitos. Enfermería Global, n. 29, 2013.

SILVA, J.P.G. et al. Consulta de enfermagem a idosos: instrumentos da comunicação e papéis da enfermagem segundo Peplau. Esc. Anna Nery, v. 19, n. 1, 2015.

TEIXEIRA, C. C. et al. Aferição de sinais vitais: um indicador do cuidado seguro em idosos. Texto Contexto Enferm, Florianópolis, v. 24, n. 4, p. 1071-1078, 2015.

WEGNER, W. et al. Educação para cultura da segurança do paciente: Implicações para a formação profissional. Escola Ana Nery, v. 20, n. 3, 2016. 